\title{
Disaster Preparedness of the Residents of Tabuk City: An Assessment
}

\author{
Jovy C. Ao-wat, Florentina B. Carbonel
}

Kalinga State University, Philippines

Received: 01 Oct 2020; Received in revised form: 18 Dec 2020; Accepted: 25 Dec 2020; Available online: 31 Dec 2020

(C2020 The Author(s). Published by Infogain Publication. This is an open access article under the CC BY license

(https://creativecommons.org/licenses/by/4.0/).

\begin{abstract}
The descriptive survey method was employed and used a set of a questionnaire in gathering needed data in the study. The study revealed that the majority of the respondents who contributed to the study were males, the majority were college level, and the majority were within the age group 41-50. The majority of the respondents claimed that they had enough knowledge of hazards and disasters imparted to them by the concern of non-government organizations and government organizations at the barangay hall, school, and media. Thus, from the findings, respondents were aware and given knowledge on disaster preparedness they acquired at barangay and school through seminars, pieces of training, and drills they participated in. The results of the findings are very much appreciated the best practices to enhance the disaster preparedness of the residents of Tabuk City:
\end{abstract}

1. Residents should religiously apply what they have learned from the pieces of training and simulations imparted to them by the governments and non-government organizations.

2. Disaster preparedness practices of the residents of Tabuk City should be followed by other residents.

Keywords-disaster preparedness, disaster management, manmade disasters, natural disasters.

\section{INTRODUCTION}

A disaster is a disruption of the functioning of a community or a society involving widespread human, material, economic or environmental losses and impacts, which exceeds the ability of the affected community to cope using its resources. Although the categories and causes of disasters may differ, therefore, a disaster plan should address disaster impacts. Disaster preparedness is an action that ensures the resources necessary to carry out an effective response are available before the disaster when needed. Disaster preparedness is preparations and adjustments such as storing food and water, preparing a household emergency plan, emergency kit, and other activities that reduce risk or injury and damage. Disaster preparedness is a healthprotective behavior, so the behavioral approaches have taken center stage as a means of it.

The Theory of Planned Behavior is a guide for investigating the antecedents of behavior. A central factor in the Theory of Planned Behavior is the individual's intention to perform a given behavior. These are assumed to capture the motivational factors that influence behavior. There are three motivational factors. First, it is the attitude toward the behavior and refers to the degree to which the individual has a favorable or unfavorable evaluation of the behavior in question. Second, it is the social factor termed subjective norm refers to the perceived behavioral control refers to the perceived ease or difficulty of performing the behavior. As a general rule, the more favorable the attitude and subjective norm toward a behavior, and the greater the perceived behavioral control, the stronger should be a person's intention to perform the behavior under consideration. The intention, in turn, is viewed as one direct antecedent of actual behavior. However, the level of success will depend not only on one's intention but also on such partly non-motivational factors as the availability of requisite opportunities and resources that represent people's actual control over the behavior. The 
Theory of Planned Behavior can be directly applied in the domain of disaster risk reduction (Nahafi, 2017).

Protection Motivation Theory was developed by Rogers in 1975 which describes how individuals are motivated to react in a self-protective way towards a perceived health threat. Protective Motivation Theory can be used and expanded to inform and improve public safety strategies in natural hazards (Westcott, 2017).

The Person Relative Event Theory emphasizes the relationship between the level of appraised threat relative to person resources and personal responsibility. The theory uses to investigate the impact of negative threat appeals on preparedness behavior regarding both earthquakes and tornadoes. Person Relative Event Theory predicts differences in coping behavior based on the level of threat under various conditions of personal responsibility (Mullis, 1998).

Another theory that can use in disaster preparedness is the Protective Action Decision Model Theory. The Protective Action Decision Theory integrates the processing of information derived from social and environmental cues with messages that social sources transmit through communication channels to those at risk. The Protective Action Decision Model Theory identifies three critical pre-decision processes (reception, attention, and comprehension of warnings or exposure, attention, and interpretation of environmental/social cues) - that precede all further processing. The revised model identifies three core perceptions - threat perceptions, protective action perceptions, and stakeholder perceptions - that form the basis for decisions about how to respond to an imminent or longterm threat. The outcome of the protective action decisionmaking process together with situational facilitators and impediments produces a behavioral response (Lindell, 2012).

Theories discussed applied to disaster preparedness there is a need for this study to be conducted to assess the disaster preparedness of the constituents of Tabuk City.

\section{METHODOLOGY}

The descriptive -survey method was employed in the study with set of questionnaires as the main instrument in gathering the needed data in the study.

The tool that was used as to the population of this study was random sampling. Random sampling is a technique in which each sample has an equal probability of being chosen. A sample chosen randomly is meant to be an unbiased representation of the total population (ecnomicstimes.com).

The data were retrieved tabulated, analyzed and evaluated. The results were subjected to descriptive statistical treatment. The Likert Scale and Weighted Mean were used to quantify the responses of the respondents of the identified objectives of the study.The following were used to measure the following; frequency, percentage; and, weighted mean.

\section{RESULTS AND FINDINGS}

Demographic Profile of Respondents

A total of 399 individuals were the population in the study. Thirty-seven (37\%) were in the age group $41-50$. Thirty percent (30\%) were 51 years and above, another twenty percent $(20 \%)$ were in the age 30 - 40 age group the remaining thirteen percent (13\%) were in the 22- 29 age group.

The gender ratio of the respondents shows that majority of the respondents were sixty-three percent (63\%) males and thirty-seven percent (37\%) females.

The educational attainment of the respondents revealed that sixty-six percent (66\%) were college level while twentythree percent were (23\%) high school, and seven percent (7\%) reached elementary level.

Thus, found out that the majority who contributed to the study were male who belongs to the $41-50$ age group who at the same time reached college level.

Awareness of the Residents about the policies on disaster preparedness

Concerning awareness about disaster sixty-nine percent $(69 \%)$ of the respondents knew disaster preparedness. Thirty-one percent $(31 \%)$ of the respondents knew disasters but they do not know what to do in case this disaster will strike their barangays and no idea whom they should call in time of any disaster.

Learning hazards and disasters is part of sustainable development, so it must involve every society, government, non-governmental organizations, and the professional and private sector. Disasters an indicator of underdevelopment reduces disaster risk requires integrating Disaster Risk Reduction Policy and Disaster Risk Management practice into sustainable development goals that hazards and risks information may be used to inform a broad range of activities to reduce risks(preventionweb.net).

Places Learned About Hazards and Disasters 
The figure presents results which show that fortyeight percent (48\%) of respondents indicated that they had learned about hazards at the barangay hall. Twenty percent (20\%) of respondents learned about hazards at school the remaining twenty-two percent $(22 \%)$ said they learned about it from home (radio, TV, internet, newspaper).

It shows that the respondents have broadened their knowledge on hazards and disasters in the barangay seminars and pieces of training imparted by the concerned agencies of the city government of Tabuk. The respondents also gained knowledge on hazards and disasters in the school where they attended on hazards and disasters are supplemented through their access to radio, TV, newspaper, and internet they have at home.

Broadening knowledge on hazards and disasters at barangay, school seminars/pieces of training, and at home manifest their importance in disaster preparedness. International Decade For Natural Disaster Reduction (UNIDNDR) noted that "to get people in a preventive way, and to see the links between disasters, development, and environment, one needs a mind-set that is best developed at an early age. A culture of prevention is something that forms over time (UN-IDNR). Therefore, cultural approaches to disaster preparedness in home, school, and community to have real success.

\section{Disaster That Will Affect Tabuk City}

Every day, there are news reports about cities stricken by natural or technological disasters. This is likely to continue, and become worse - unless we change our policies and actions on environment and development. Why are cities at risk? First, more people are settling in areas vulnerable to hazards. Second, rapid population growth and migration make it difficult for authorities to protect people from disasters. Finally, urbanization is upsetting balances in ecosystems, with added disasters as a result. What these cities have in common is that they all have been stricken recently by major natural disasters. Disasters have become part of the image and psyche of these places(mona.uwi.edu). Thus, all expect to experience any disasters.

From the results presented, the majority of the respondents constituting thirty-five percent $(35 \%)$ thought that our country could be affected by floods, twenty-eight percent $(28 \%)$ thought soil erosion/landslide. Twenty-one percent $(21 \%)$ regarded storms as a threat in Tabuk City; Fire mentioned as a disaster with eighteen percent (18\%). Furthermore, sixteen percent $(16 \%)$ of the respondents indicated that technological disasters would ever affect Tabuk City.

The information gathered signifies that floods, soil erosion/landslide, storm, fire, and technological disaster will affect more Tabuk City.

Flood refers to too much water in the wrong place. Causes are both natural and human, including dam failures, blocked drainage systems, burst water mains, and storm. Floods are the most frequent disasters and growing more rapidly than other disasters. Urban concerns: Rapid urbanization is a factor in the increase of floods. Flash floods a growing issue due to concrete/compacted earth absorbs little water, the decline of open spaces, engineering works that divert river flows, and weak city drainage systems. Inappropriate housing on river banks or near deltas (due to construction location) is a concern.

Rocks and soil sliding rapidly downhill are known to be landslides. They varied from mudflows, rock falls, avalanches triggered by earthquakes, volcanic eruptions, storms, waterlogged soil, and heavy construction. Landslides caused by the growing amounts of built housing on/below steep slopes, on cliffs, or at river mouths of mountain valleys and often on illegally occupied land housing ignores planning/building codes.

Fire spreads over large areas and can get out of control. Urban fires stem from industrial explosions or earthquakes. Fire risks are increasing due to heavy building density, new building materials, more high-rise buildings, greater use of energy in concentrated areas.

Technological Disasters are systems failures, chemical accidents, industrial explosions, spillage in the ground, water, or air. Can be a secondary disaster following earthquakes and other natural disasters (natural/ technological compound disasters, or "na-techs") Urban concerns are $\mathrm{Na}$-tech risks are increasing with rapid, uncontrolled urbanization and industrialization (mona.uwi.edu).

Further, Janneck (2015) emphasized that as the world becomes more urban and climate change picks up pace natural disasters remain one of the greatest threats to human health and stability.

Cities are becoming larger, more humans on the planet are becoming urban, and city leaders are turning their attention toward the importance of preparedness and response to natural disasters. 
It is anticipated that the majority of the world's population growth in the next several decades will be in the cities of low and middle-income countries. Many of these cities are particularly vulnerable to flooding and extreme weather, located in low-lying coastal zones. Within these cities, slum settlements are built on the most vulnerable lands, prone to landslides, or abutting waterways in flood zones.

Many natural disasters, particularly storms and hurricanes, are thought to be increasing in severity in part due to climate change (Janneck,2015).

Measures Learned on Disaster Preparedness

The types of drills learned by the respondents. Fiftyfive percent (55\%) of the drills given to the respondents, twenty-five percent (25\%) evacuation drill, ten percent (10\%) first aid drill, and five percent $(5 \%)$ rescue drill.

The respondents taught on emergency calls. Wherein when calling for police, ambulance, fire or other emergency services, thus, they are taught: to be prepared; to describe WHAT, WHEN, WHERE, WHAT is happening, WHO you are and how to call you back; do not hang up until told to do so. For personal safety they were taught should program that the numbers of agency/s should be on the phone so that "In Case of Emergency" they can call the concerned agency/s for help.

The respondents claimed that they were taught what fire is all about. They added that if they see a fire they put out small fires with fire extinguishers or cover the source of fuel with a blanket. And for modern fire extinguisher use, religiously taught to the respondents:

1. remember "P.A.S.S." (Pull safety pin from handle. Aim at the base of the flame. Squeeze the trigger handle. Sweep from side to side at the base of the flame);

2. shut off the source of fuel if safe to do so (e.g., gas);

3. activate fire alarm;

4. alert others;

5. Call emergency telephone number and report the location of the fire;

6. evacuate building;

7. close doors and windows.

8. if the respondents hear a fire alarm: treat as a real emergency; follow building evacuation procedures; never open a closed door without checking first for heat; do not open a hot door;
9. If the respondents caught in smoke they stated the following drill taught to them: drop down on knees and crawl out; breathe shallowly through your nose; hold breath as long as possible; use a damp cloth over mouth and nose;

10. If trapped in a room by the fire, again the respondents claimed that: block smoke from entering with a damp cloth, under the door; retreat closing as many doors as possible; signal and phone your location;

11. If a person or their clothing is on fire, the respondents emphasized the following drill taught to them; stop where you are; drop to the ground and roll over; and,

12. If another person is on fire, the respondents revealed that they taught to them: push the person who is on fire down, roll him cover with blanket, rug, or coat.

Earthquake to the respondents is an avoidable disaster drill on the earthquake taught to them. The following were the drills:

1. if there is a shaking of the ground somebody should shout and instruct loudly: "Earthquake position: Drop, Cover and Hold On";

1. after the shaking of the ground is over, evacuate outdoors and stay away from the building;

2. if inside buildings, the door should be opened fully by the person who is closest to the door;

3. the open fire should be extinguished by the person who is near an open flame;

4. the dropdown on knees;

5. cover your head, neck, and face;

6. go under a sturdy desk or table to protect the head and neck and as much the body as possible;

7. hold on to cover;

8. stay away from tall and heavy furniture or heavy equipment, and overhead hazards;

9. do not use elevators;

10. in a wheelchair, lock it and take the "brace position" covering head and neck;

11. follow ushers instructions for orderly evacuation; and, 
12. move away from buildings, walls, power lines, trees, light poles, and other hazards.

Flood is also experienced by the respondents in lowland areas and flood-prone areas in Tabuk City. The respondents indicated that the following drills: to safeguard their lives and properties: Follow early-warning instructions. Evacuate to higher ground or shelter-in-place. - Slow rise flooding: Given sufficient notice to evacuate before flooding, protect records and electronic equipment as best as possible. Take normal actions for building evacuation and proceed to a haven. $\cdot$ Sudden severe flooding. Evacuate all affected spaces immediately. Relocate to a safe place on the upper floors of the building, taking Go Bucket or Bag and emer- 32Disaster and Emergency Preparedness: Guidance for Schools agency notebook or clipboard with you. Do NOT try to wade through floodwaters of any depth. Do NOT try to leave the building in a car. If you must evacuate, wear life-jackets or similar flotation devices.

Hazardous Materials Release. Evacuate upwind to haven or shelter-in-place, closing and sealing windows, air-ducts. • Chemical spills or suspicious materials. If possible, limit release at the source and contain the spill. Shut down equipment. Evacuate the immediate area. If danger extends beyond the immediate area, pull the fire alarm, and follow the building evacuation and assembly procedure. The first witness of the hazardous materials leak/spill: call emergency telephone number give details of materials and location, and the number of people in the vicinity. - Gas leak. Do not pull the fire alarm - this could cause an explosion. Leave the area and call the emergency telephone number. Issue alert using public address system or door-to-door. Evacuate the building following building evacuation and assembly procedures. Explosion. Drop and cover under desk, tables, or other furniture that will protect you against flying glass and debris. When it is safe refer to the Emergency Call Section and immediately report an explosion. Leave doors open to permit exit, if the building is damaged. Stay away from outside walls and areas where there are large pieces of glass and/or heavy suspended light fixtures. Standby for further instructions from your incident commander."Our disaster preparedness initiatives now involve different barangays in our area. Even students like you are now encouraged to help inform others on disaster preparedness that's why we are holding this activity. You will serve as our partners in disseminating what we have shared with you so we can at least lessen the effects of any disaster that might come," Castillo said. He added, "Now, we are not just concerned about disaster response. We now cover preparation against potential disasters, reducing and managing risks, and more importantly, we also focus on rehabilitation of areas affected by disasters."(Cajulao2012). It aims to ensure that disaster preparedness and effective response are in place before and after the occurrence of any calamity (Macatangay, 2012).

Practicing, monitoring, and improving Hold simulation drills to practice, reflect upon, and update your plan School drills should be tailored to expected hazards. Every school should conduct at least three (3) fire drills per year and at least one full simulation drill. Schools in earthquake or flood-prone areas should also practice for these hazards. For every drill that you perform with a prior announcement, be sure to perform one without a prior announcement. Try them with different scenarios, at different times of the day. Try them when the school principal is there and when he or she is not there. The purpose of a drill is to prepare for the unexpected, so if you make it too easy, you won't learn how to adapt to the real situation. Drills should always be treated as "the real thing." Good drills are a learning process. They begin with preparation by staff, providing an opportunity to train students in classroom groups, remember procedures, and check on provisions. The simulation itself is an experiential learning opportunity. Following 39 School Disaster Management the drill, students can debrief with teachers in the classroom. An "all-school" faculty and staff meeting is an important way to debrief and to discuss ways to improve upon both mitigation measures and response preparedness. The most important part of any drill is the discussion and the updated action plan that comes from the experience. (World Bank Group, 2011).

The NDCC is implementing a five-year (2006-2010) Hazards Mapping and Assessment for Effective CommunityBased Disaster Risk Management (dubbed as READY) in partnership with UNDP and AusAid. This project aims to institutionalize and standardize DRM measures and processes at the national level as well as empower the most vulnerable local municipalities and cities in the country. The READY Project targets 27 high-risk provinces and has three main components, namely; - Multi-hazard Identification and Disaster Risk Assessment: Development of multi-hazard mapping for landslide, flood, earthquake, storm surge, and other related hazards - Community-based Disaster Preparedness: Development of Information and Education Campaign strategies and materials for specific target groups and Installation of Community-Based Early Warning Systems (rain/tide/water level gauges and landslide/tsunami signages) 
- Mainstreaming/Institutionalization of Risk Reduction into the Local Development Planning Process: Building a platform for efficient donor coordination to facilitate mobilization of resources (financial, capability upgrade, and technical expertise) (Palacio 2007).

\section{CONCLUSION}

The findings from this study showed that the majority of the respondents who contributed to the study were males. The majority of the respondents were college level, and the majority of the respondents were within the age group 41 -50 .

Regarding hazards and disaster knowledge, the majority of the respondents thought they had enough knowledge imparted to them by the concerned nongovernment organizations and government organizations at the barangay hall, school, and media.

From the findings, respondents were aware of disaster preparedness with the knowledge they acquired at barangay and school as well as from emergency drills conducted as separate training programs at barangay and school respondents who contributed to the study stated that all emergency taught to them in the barangay. The respondents claimed that they rehearsed emergency drills, first aid, evacuation drills, and rescue drill at schools as a result of workshops.

\section{RECOMMENDATIONS}

The results of the findings are very much appreciable some best practices to enhance the disaster preparedness of the residents of Tabuk City:

1. The residents should be appreciated religiously in applying what they have learned from the pieces of training and simulations imparted to them by the governments and non-government organizations.

2. These appreciable practices on disaster preparedness should be followed.

\section{REFERENCES}

[1] Ahmedabad Action Agenda for School Safety, 2007

[2] Annual Report.Tabuk City, Kalinga 2014.

[3] Annual Report.Tabuk City, Kalinga 2015.

[4] Annual Report.Tabuk City, Kalinga 2016.
[5] Anderson, A.2010. Combating Climate Change through Quality Education.US Washington DC.

[6] Comprehensive Land Use Plan, Tabuk City 2013 - 2022.

[7] Cujalao, MV D. (2012). Teachers, Students Participate in Disaster Preparedness Symposium, Earthquake Drill. Report fro Government of the Philippines.

[8] Disaster Management Training Programme(DMTP), 1992. An Overview of Disaster Management: $2^{\text {nd }}$ Ed. United Nations Disaster Management Programme: University of Wisconsin Disaster Management Centre.

[9] ISDR 2006 - 2007. World Disaster Reduction Campaign:Disaster Risks Reduction Begins at School. Geneva

[10] Janneck, L. (2015). Preparing for natural Disasters is Becoming Even More.

[11] Lindell, 2012. The Protective Action Decision Model: Theoretical Modifications and Additional Evidence. PubMed.

[12] Macatngay, LS - PIAV Camarines Sur.

[13] Mamogale, H.(2011). Assessing disaster preparedness of learners and educators in Soshanguve North School.Disaster Management Training and Education Center for Africa.University of the Free State.

[14] Mullis, John Paul, 1998. Person-Relative Event Theory of Coping With Threat. ERIC.

[15] Nahaki, Mehdi (2017). The Theory of Planned Behaviour on Disaster Preparedness. PLOS Current Disaster.

[16] Palacio, A.(2007)Emergency Preparedness in the Philippines: A Country Perspective.

[17] Paton,D. and Johnson,D. 2001. Disasters and Communities: Vulnerabilty, Resilience, and Preparedness, Disaster Prevention and Management.

[18] Parker, D. 1992. The Mismanagement of Hazards.London: James \& James.

[19] Singh,D. 2007. Disaster Management and the Role of Armed Forces. Pune: University of Pune, College of Defense Management.

[20] United Nations (2001).International Disaster for Natural Resources.

[21] Westcott, Rachell (2017). Expanding Protection Motivation Theory: Investigating an Application to Animal Owners and Emergency Respondents Bushfire Emergencies. BMC Psychology.

[22] https://www.mona.uwi.edu.cardin/virtual

[23] https://reliefweb.int/report/philippines/teachers-studentsparticipate-disaster-preparedness-symposium-earthquakedrill

[24] https://reliefweb.int/report/philippines/dilg-enjoins-lgussupport-operation-listo

[25] http://unpan1.un.org/intradoc/groups/public/documents/APCI TY/UNPAN029434.pdf

[26] www.preventionweb.net 